\title{
The use of statistical methods by MBA graduates in South African management and its implications for curriculum design
}

\author{
Trevor Wegner \\ Department of Statistical Sciences, University of Cape Town, Rondebosch 7700, Republic of South Africa \\ Stephanie Stray \\ Warwick Business School, University of Warwick, Coventry CV4 JAL, United Kingdom \\ Peter Naudé \\ Manchester Business School, Booth Street West, Manchester M15 6PB, United Kingdom
}

Received November 1993, accepted December 1993

\begin{abstract}
With this study we aim to identify the degree of penetration of statistical methods in South African management. Consequently, that section of the management population with past exposure to quantitative methods is targetted. Thus the target population was all MBA alumni from South African Business Schools operating in South African companies. A response rate of $27 \%$ (408 usable responses) was achieved. The findings of this study correlate highly with those of a similar survey conducted in the United Kingdom in 1991. In addition to reporting these findings, we also sought to examine the implications of these results on future statistical methods course planning. We recommend a change in teaching strategy to promote greater utilization of this discipline in practice.
\end{abstract}

Met hierdie studie word gepoog om die mate waartoe statistiese metodes onder Suid Afrikaanse bestuur gebruik word, te identifiseer. Die studie was gemik op die gedeelte van die bestuurspopulasie wat reeds in 'n MBA-program aan kwantitatiewe metodes blootgestel was. Die steekproefpopulasie was dus alle MBA-alumni van Suid Afrikaanse Bestuurskole wat by Suid-Afrikaanse maatskappye werksaam is. Altesaam 27\% (408 bruikbare antwoorde) antwoorde is ontvang. Die bevindinge van hierdie studie korreleer gunstig met dié van 'n soortgelyke studie wat in 1991 in Brittanje gedoen is. Nie alleen word die resultate van hierdie ondersoek gerapporteer nie, maar met hierdie studie word ook oorweging geskenk aan die implikasies van die bevindinge vir toekomstige beplanning van kursusse in statistiese metodes. Veranderings in onderrigstrategie word aanbeveel om die gebruik van toepaslike tegnieke aan te moedig.

*To whom correspondence should be addressed.

\section{Introduction}

Quantitative methods has been an integral component of every academic management education programme for at least two decades in South Africa and even longer in Europe, Britain and the United States. It is appropriate that each management discipline should subject itself to periodic self-appraisal to confirm or reassess its relevance to the management education process. Quantitative methods is no exception. However, only two studies to assess the current status of the discipline within South African management (Wegner, 1983 and Juritz, Money, Affleck-Graves \& Du Toit, 1988) have been reported in the past decade. A further rationale for undertaking another study in South Africa is the fact that a similar study by Naudé, Stray \& Wegner (1991) amongst United Kingdom management has recenty been completed and would serve as a useful basis for comparison for the South African experience.

This study serves two broad purposes. Firstly, it aims to identify the level to which quantitative methods have been integrated into management decision making in South Africa and secondly, it examines the implications of these findings for future quantitative methods course planning in South African management education.

This study differs from almost every other study into quantitative methods practices in management by focussing only on that section of the management population with past exposure to quantitative methods through an MBA programme. Thus the target population was all MBA alumni from South African Business Schools operating in South African companies. This removes one of the commonly identified factors for non-implemetation namely, ignorance of the discipline from the study.

\section{Literature review}

In the early seventies Vandell (1970: 5) identified quantitative analysis and electronic data processing as two powerful emerging forces in management. It is a fail accompli that the computer revolution has happened over the past two decades. However, studies exploring the extent to which quantilative methods thinking has penetrated the domain of management decision making have generally reported less dramatic developments. Some of these more recent studies are reviewed here.

The studies which are reported differ widely in their sampling methods, choice of techniques, and questionnaire design. Consequently, it will not be possible to draw firm conclusions about the scale of penetration of quantitative methods into decision making in mainly American and European management. However, certain pauerns can be detected and these will be highlighted. All studies reviewed below will be examined from the following points of view: (i) the identification of the most frequently used techniques; (ii) the percentage of techniques examined which are in frequent use; and (iii) the identification of hinderances which inhibit the further use of quantitative methods in management practice. This study will focus only on statistical methods as a subset of the broader range of Quantitative Methods discipline. 
While not representing the management profession, the results of a survey carried out amongst members of the Institute of Statisticians (Pridmore \& Reese, 1988) provide an insight into the most frequently used techniques by professional statisticians. In decreasing order of usage levels, the top 50\% of techniques employed are data collection and presentation, experimental design and analysis, hypotheses testing, time series and forecasting and surveys and opinion polls. In a recent joint United Kingdom-Europe study (involving Denmark and Greece), Wisniewski, Jones, Halikias, Bourantas, Kristensen \& Ostergaard (1990: 18) found that extensive use was reported by the 93 respondents across the three countries of the following statistical methods with respondent frequencies greater than 25\%: basic statistics $(65 \%)$, simulation $(38 \%)$, smoothing methods $(38 \%)$, regression (37\%), inventory control (25\%), and quality control (25\%). Of interest, in terms of statistical techniques, respondents were least familiar with a range of multivariate and non-parametric methods (1990: 20). Only six of the 27 techniques examined are used regularly by $25 \%$ or more of responding companies. Usage patterns of statistical methods in the USA have been researched by Kathawala (1988). He reported on 226 responses of a survey of large manufacturing firms, service organizations and small businesses in the USA. The five top ranked techniques, in terms of regular usage, were identified as follows: forecasting (72\%), statistical sampling (45\%), simulation (44\%), regression analysis (35\%), and ANOVA $(35 \%)$. This study by $\mathrm{Ka}$ thawala was a replication of an earlier study by Green, Newson \& Jones (1977) which reported that the most frequently used techniques were sampling $(50 \%)$, stock control (45\%), regression (42\%), and time series (40\%).

In terms of the number of techniques in frequent use, the 1977 study of Green et al. reported that only $25 \%$ of the responding companies had frequent or extensive use of 7 of the 19 quantitative methods examined; and 9 out of 19 were not used by over $60 \%$ of the responding companies (Kathawala, 1988: 982). Kathawala's finding was more pessimistic. His study found that only 7 out of the 28 techniques surveyed are listed as being frequently or extensively used by
$25 \%$ or more of the responding companies. Altogether 11 out of the 28 techniques are largely unused by over $60 \%$ of the responding firms (1988: 984). Kwathawala concluded that the results are far from satisfactory in terms of increased penetration of quantitative methods into American management decision making. In a second recent survey reported in the USA, Coccari (1989) surveyed small and medium-sized manufacturing firms. He concluded that forecasting methods 'seem to have a broader appeal than other quantitative techniques' (1989: 72).

The South African management community has only been surveyed twice in the past ten years. The 1983 study by Wegner reported that of the 165 Johannesburg Stock Exchange companies who responded, descriptive statistics (52\%) and forecasting methods - including regression and time series - $(53 \%)$ were the most widely known and used methods. Only between $20 \%$ and $32 \%$ of respondents reported using inferential statistics and simulation on a periodic to regular basis (1983: 122). Fewer than 10\% of all respondents reported using any other technique on a regular basis. In 1988 the second study - based on 42 responses was reported by Juritz, Money, Affleck-Graves \& Du Toit (1988) on the use of statistics in South African Commerce and Industry. They found that routine use was made of graphical display and data summary by $80 \%$ of respondents, basic statistical methods by $70 \%$ of respondents, and forecasting methods by $60 \%$ of respondents. Only $40 \%$ of respondents reported routine use of analysis of variance, regression analysis, time series, and quality control methods. Other statistical methods such as survey sampling, contingency tables, multivariate techniques and non-parametric methods were reported as routinely used by a minority of respondents which ranged from 20\% down to 5\% (1988: 62).

Summarized in Table 1 are the six studies reported above and a pattern that has evolved in recent times is highlighted. Data collection and graphic display (which includes basic statistics) has emerged from the six studies reported as the most frequently used (i.e. $50 \%$ to $80 \%$ ) set of statistical methods. Only moderate usage (i.e. between $30 \%$ and $50 \%$ overall) is reported for most of the remaining techniques

Table 1 Comparison of usage frequency of statistical methods from six studies (1977-1990)

\begin{tabular}{|c|c|c|c|c|c|c|}
\hline $\begin{array}{l}\text { Statistical } \\
\text { techniques }\end{array}$ & $\begin{array}{c}\text { IoS } \\
\text { (1988) }\end{array}$ & $\begin{array}{c}\text { Juritz } \\
\text { et al. } \\
\text { (1988) }\end{array}$ & $\begin{array}{l}\text { Katha- } \\
\text { wala } \\
\text { (1988) }\end{array}$ & $\begin{array}{c}\text { Green } \\
\text { et al. } \\
(1977)\end{array}$ & $\begin{array}{c}\text { Wisnie- } \\
\text { wski } \\
(1990)\end{array}$ & $\begin{array}{l}\text { Wegner } \\
\text { (1983) }\end{array}$ \\
\hline
\end{tabular}

\begin{tabular}{lcccccc}
\hline Basic statistics \& & & & & & & \\
graphical display & $1^{*}$ & $80 \%$ & - & - & $65 \%$ & $52 \%$ \\
Experimental design & 2 & $40 \%$ & $35 \%$ & - & - & - \\
Inferential methods & 3 & $70 \%$ & - & - & - & $33 \%$ \\
Forecasting methods & 4 & $40-60 \%$ & $72 \%$ & $40 \%$ & $38 \%$ & $54 \%$ \\
Sampling & 5 & - & $45 \%$ & $50 \%$ & - & - \\
Quality control & - & $40 \%$ & - & - & $25 \%$ & - \\
Regression analysis & - & $40 \%$ & $35 \%$ & $42 \%$ & $37 \%$ & $54 \%$ \\
Simulation & - & - & $14 \%$ & - & $38 \%$ & $32 \%$ \\
Inventory control & - & - & - & $45 \%$ & $25 \%$ & $27 \%$ \\
\hline
\end{tabular}

* The los study only ranked the top $50 \%$ of techniques most frequently used. 
listed in Table 1. Almost all other statistical methods not listed in Table 1 do not appear to be in common use (i.e. regular usage levels below 10\%).

In addition to usage analysis, a further major component of most studies into quantitative methods applications focuses on the identification of hinderances which inhibit the further penetration of these methods into management practice. All three US studies established that amongst the topranking barriers were: the benefits of using techniques are not clearly understood by managers, and managers lack knowledge of quantitative techniques (Green et al., 1977; Kathawala, 1988; Coccari, 1989). Of the 15 ranked order of barriers listed by Kathawala (1988: 987), the majority of the top order barriers relate largely to a lack of knowledge and confidence and can be described as mainly human-oriented hinderances. The lower rank order barriers relate to mainly techrical hinderances such as lack of data, cost and computing difficulties. In the 1983 study reported by Wegner (1983: 122), the lack of understanding by the line manager and inadequately trained personnel for implementation were cited as the two primary reasons by responding companies for reporting either no usage or very limited usage of quantitative methods in decision making. Wegner concluded that ' $70 \%$ of all the problems associated with the application of these techniques are attributed to the human element' (1983: 122).

Lack of management support and no established support group within the organization were the top two reasons given by UK respondents in the Wisniewski (1990) study.

There is general concensus amongst researchers that human-oriented factors are the most significant barriers to more widespread use of statistical methods in management. A disturbing observation is that this barrier has not diminished over the years. It was reponed in the mid-1960s by Vatter (1967) and still features high on the list of hinderances in the $1990 \mathrm{~s}$. It is also a inter-country phenomena. It is as prevalent in the USA as it is in the UK and South Africa.

\section{Empirical findings}

In this section the findings of a survey conducted in 1992 amongst Business School management graduates operating in South African companies are presented. The MBA alumni lists of the four major RSA Business Schools, namely the University of Cape Town, Witwatersrand University, University of South Africa, and Stellenbosch University were used as the sampling frame. These alumni account for over 90\% of all South African MBA graduates annually. A mailed questionnaire identical to the one used in the Naudé, Stray \& Wegner (1990) study conducted in the United Kingdom was used. A response rate of $27 \%$ (408 usable responses) was achieved using a clustered random sampling approach.

Of the 408 responses, $256(63 \%)$ identified themselves as users and $152(37 \%)$ as non-users of quantilative methods. The UK study (Naudé et al., 1991) reported that 66\% of respondents used statistical techniques, while $34 \%$ did not. More than a quarter of the South African non-users (28\%) envisaged employing statistical methods in the future. The most common reasons given for non-use were 'lack of need' and 'non relevance to job or company activity'. It should be noted that in this study only the explicit use of statistical methods in management practice will be examined. An aspect which is not explored in this study, but which could form the basis for further research, is the extent to which non-users may implicilly apply statistical reasoning in their decision making.

To establish if non-response bias exists, the profile of responses between identified users and non-users as classified by management level, functional area, and economic sector were examined. These profiles are shown in Table 2.

For both users and non-users, the majority of respondents were top management (about 60\%) and about one-third were middle management. No difference in profile exists. In terms of functional area, general management (users 43\%, non-users 50\%) were the largest representative group in both categories. All the major functional areas in management are also well represented as shown in Table 2. A good cross-section of economic sectors are represented with a slight bias towards Retail/Banking (users 14\%, non-users 15\%), Engineering, Chemicals/Energy, Construction and Consultancy (each approximately $10 \%$ representation).

Table 2 Profiles of users and non-users by management level, functional area and economic sector

\begin{tabular}{|c|c|c|}
\hline & \multicolumn{2}{|c|}{ Percentages of } \\
\hline & $\begin{array}{c}\text { users } \\
(n=256)\end{array}$ & $\begin{array}{c}\text { non-users } \\
(n=152)\end{array}$ \\
\hline \multicolumn{3}{|l|}{ Mangacisent keved } \\
\hline Top & 58 & 64 \\
\hline Middle & 36 & 32 \\
\hline Junior & 6 & 4 \\
\hline \multicolumn{3}{|l|}{ Functional area } \\
\hline General management & 43 & 50 \\
\hline Marketing/sales & 11 & 18 \\
\hline Finance/accounting & 9 & 12 \\
\hline Production/operaions & 10 & 5 \\
\hline Humm resources & 6 & 3 \\
\hline Computer suppon & 11 & 5 \\
\hline Other & 10 & 7 \\
\hline \multicolumn{3}{|l|}{ Ecomonic sector } \\
\hline Metal and mining & 7 & 7 \\
\hline Chemicalstenergy & 10 & 10 \\
\hline Pharmaceuticals & 4 & 3 \\
\hline Engincering & 10 & 14 \\
\hline Textiles/peper & 6 & 4 \\
\hline Food/drink & 6 & 3 \\
\hline Consenuction & 8 & 11 \\
\hline Trenspont & 4 & 3 \\
\hline Retailing/tanking & 14 & 15 \\
\hline Printing/publishing & 1 & 1 \\
\hline Consulting & 12 & 11 \\
\hline Public service & 2 & 3 \\
\hline Education & 2 & 1 \\
\hline Computer services & 3 & 5 \\
\hline Other & 11 & 9 \\
\hline
\end{tabular}


While marginal differences were noted in the spread of users versus non-users across the major functional areas and economic sectors, these differences do not appear to be significant.

Since the percentage of non-user respondents is relatively large in terms of the response sample (i.e. almost $40 \%$ ), non-response bias from non-users would appear to be minimal. In addition, the similar user and non-user profiles across management levels, functional areas and economic sectors indicate that a representative cross-section of South African management with quantitative methods exposure have been surveyed through the sample.

\section{User awareness}

The remainder of the empirical findings relate to the 256 user responses. The first question asked of users of statistical methods was their level of awareness of a range of statistical techniques. The techniques are separated into High, Moderate and Low awareness categories in Table 3. The equivalent awareness levels for the United Kingdom study are also shown together with a rank ordering of techniques by awareness levels.

In Table 3 the view is confirmed that there is high awareness (above $80 \%$ ) of the introductory statistical methods as expected given the nature of the sampling procedure, and moderate to low awareness of the intermediate and specialist interest statistical techniques.

An almost identical rank ordering of techniques in terms of awareness is found between the RSA and UK user respondents. However, the awareness levels for techniques in

Table 3 Respondent awareness of statistical techniques

\begin{tabular}{|c|c|c|c|c|}
\hline \multirow{3}{*}{ Statistical method } & \multicolumn{4}{|c|}{ Awareness } \\
\hline & \multicolumn{2}{|c|}{$\begin{array}{c}\text { RSA } \\
(n=256)\end{array}$} & \multicolumn{2}{|c|}{$\begin{array}{c}\text { UK } \\
(n=420)\end{array}$} \\
\hline & $\%$ & Rank & $\%$ & Rank \\
\hline \multicolumn{5}{|l|}{ High awareness } \\
\hline Data collection and presentation & 100 & 1 & 98 & 1 \\
\hline Forecasting models & 96 & 2 & 92 & 3 \\
\hline Regression and correlation & 94 & 3 & 92 & 4 \\
\hline Probability analysis & 92 & 4 & 95 & 2 \\
\hline Hypothesis testing & 84 & 5 & 78 & 6 \\
\hline Confidence intervals & 84 & 6 & 81 & 5 \\
\hline \multicolumn{5}{|l|}{ Moderate awareness } \\
\hline Sample survey design & 77 & 7 & 74 & 7 \\
\hline Index numbers & 65 & 8 & 56 & 9 \\
\hline Contingency tables & 63 & 9 & 60 & 8 \\
\hline \multicolumn{5}{|l|}{ Low awareness } \\
\hline Multivariate models & 53 & 10 & 50 & 10 \\
\hline Quality control & 51 & 11 & 36 & 11 \\
\hline Experimental design model & 46 & 12 & 18 & 13 \\
\hline Non-parametric tests & 42 & 13 & 34 & 12 \\
\hline
\end{tabular}

the specialist areas, such as quality control, experimental design models and non-parametric tests appear significantly lower in the UK study than amongst SA user respondents.

\section{Usage levels}

The usage level of each of 13 statistical techniques were guaged on a 5-point semantic differential scale from 'none' (0) to 'extensive' (4). The mean usage level of each technique is shown in Table 4 and is a measure of the intensity of usage. The techniques have been classified into high, medium and low usage levels.

Indicated in Table 4 is the fact that there is generally low usage amongst the 256 user respondents for the majority of the statistical techniques examined. The only exceptions are the techniques of data collection and presentation (mean usage $=2.95$ ) which shows high usage, and the moderate usage of predictive techniques such as forecasting models and regression and correlation. An almost similar pattem is found amongst UK user respondents.

The mean usage levels of Table 4 measure the intensity of usage. To explore the frequency of usage, respondents ranked the three most often used techniques. Frequency is expressed as a percentage of the number of respondents who ranked a technique in the top three relative to the number of respondents aware of the given technique. Refer to Table 5.

Data collection and presentation methods enjoy the highest usage both in terms of intensity (mean score $=2.95$ ) and frequency (by $92 \%$ of users). Predictive type models such as forecasting models and regression and correlation show a moderate level of application both in terms of intensity and frequency of usage (approximately $50 \%$ of users make use of these techniques frequently). The remainder of the techniques show low and infrequently use. Frequent usage of these

Table 4 Mean usage levels - South Africa and the United Kingdom

\begin{tabular}{lll}
\hline \multicolumn{1}{c}{ RSA } & \multicolumn{2}{c}{ Mean usage } \\
& $(n=256)$ & $(n=420)$ \\
\hline High usage & & \\
$\begin{array}{l}\text { Data collection and presentation } \\
\text { Moderate usage }\end{array}$ & 2.94 & 3.01 \\
Forecasting models & & \\
Regression and correlation & 1.80 & 1.66 \\
Low usage & 1.63 & 1.14 \\
Probability analysis & & \\
Index numbers & 1.18 & 1.13 \\
Sample survey design & 1.12 & 1.26 \\
Confidence intervals & 1.02 & 1.10 \\
Quality control & 1.00 & 0.85 \\
Contingency tables & 0.92 & 0.72 \\
Hypothesis testing & 0.82 & 1.01 \\
Multivariate models & 0.66 & 0.67 \\
Experimental design models & 0.44 & 0.76 \\
Non-parametric tests & 0.38 & 0.34 \\
\hline
\end{tabular}


Table 5 Most frequently used techniques

\begin{tabular}{lc}
\hline Statistical method & $\begin{array}{c}\text { Frequency } \\
\text { of use }\end{array}$ \\
\hline Data collection and presentation & $92 \%$ \\
Forecasting models & $57 \%$ \\
Regression and correlation & $50 \%$ \\
Probability analysis & $23 \%$ \\
Sample survey design & $22 \%$ \\
Index numbers & $22 \%$ \\
Quality control & $18 \%$ \\
Confidence intervals & $14 \%$ \\
Contingency tables & $12 \%$ \\
Hypothesis testing & $7 \%$ \\
Multivariate models & $6 \%$ \\
Experimental design models & $4 \%$ \\
Non-parametric tests & $4 \%$ \\
\hline
\end{tabular}

latter techniques is confined to only a small percentage of respondents which range from $4 \%$ to no more than $23 \%$ of respondents (refer to Table 5).

As a pointer to the future use of statistical techniques, respondents were asked to identify the top three techniques considered to have potential for further application. Indicated in Table 6 is the percentage of respondents who consider that more frequent usage can be made of a given technique in their decision-making domain. The responses are expressed as a percentage of the number of respondents who were aware of the particular technique.

The three techniques which currently enjoy the most frequent usage currently, namely data collection/presentation, forecasting models and regression analysis tend also to be amongst the techniques which are considered to have greater potential for further usage. There is also a perception amongst respondents that the less used techniques of probability analysis and quality control have potential for more frequent usage in the future. Currently these latter two

Table 6 Techniques warranting more frequent usage

\begin{tabular}{lrrr}
\hline & \multicolumn{2}{c}{ RSA } & UK \\
& No. & $\%$ & $\%$ \\
\hline Greater potential for further usage & & & \\
Forecasting models & 143 & 58 & 54 \\
Probability analysis & 108 & 46 & 41 \\
Data collection and presentation & 109 & 43 & 53 \\
Regression and correlation & 87 & 36 & 32 \\
Quality control & 43 & 33 & 22 \\
Lesser potential for further usage & & & \\
Confidence intervals & 43 & 20 & 26 \\
Sample survey design & 31 & 16 & 20 \\
Hypothesis testing & 33 & 15 & 19 \\
Multivariate models & 15 & 11 & 10 \\
Non-parametric tests & 11 & 10 & 3 \\
Experimental design models & 12 & 10 & 15 \\
Contingency tables & 14 & 9 & 13 \\
Index numbers & 8 & 5 & 13 \\
\hline
\end{tabular}

techniques are used frequently by only approximately $20 \%$ of respondents.

Techniques which currently have little usage (i.e. mean usage is below 1.0 as seen in Table 4) such as Sample Survey Design, Index Numbers, Contingency Tables, Multivariate Models, Quality Control, Experimental Design Models, Non-Parametric Tests, are considered not to have much potential for further application. The UK study findings are very similar to the above findings as seen from Table 6.

\section{Benefits}

The perceived importance the 256 user respondents attached to statistical methods as a decision support function in management decision making is clearly indicated in Table 7. Between $60 \%$ and $70 \%$ of respondents see the role of statistical methods as enhancing their decision-making capabilities. This perception is shared by the UK management respondents as reported by Naudé et al. (1991: 453).

\section{Inhibiting factors}

The most significant barrier to greater usage is a human constraint. From Table 8 it can be seen that over $40 \%$ of the 256 user respondents (42\%) see the lack of statistical knowledge of their management colleagues as the major inhibiting factor. This limits the ability of respondents to communicate effectively using statistically based reports. This is also a significant factor highlighted by the UK report (33\%). The second most important inhibitor in both this study and the UK study is a technical factor of the lack of appropriate data. Altogether 35\% of South African respondents and $28 \%$ of UK respondents identified it as a problem area.

Technical problems rated more prominently than human problems overall in this study. The lack of consultativel technical support (29\%) and the lack of appropriate statistical software (28\%) appear to be more important inhibitors than the human factors of colleagues' lack of confidence in statistical methods (20\%) and respondent's own lack of confidence (13\%). In contrast, the UK study found that human barriers were marginally more significant

Table 7 Benefits derived from using statistical techniques

\begin{tabular}{lcc}
\hline Factors & $\begin{array}{c}\text { RSA } \\
(n=256) \\
\%\end{array}$ & $\begin{array}{c}\text { UK } \\
(n=420) \\
\%\end{array}$ \\
\hline Greater confidence in final decision & 68 & 52 \\
Deeper analysis of problem possible & 68 & 60 \\
Reduces subjective jugdement & 66 & 60 \\
Improves problem understanding & 61 & 60 \\
Decision justification made easier & 55 & 57 \\
Other & 15 & 11 \\
No benefits & 0 & 0 \\
Total number of mentions & 853 & \\
(excluding No benefus) & & \\
\hline
\end{tabular}


Table 8 Barriers to greater usage

\begin{tabular}{lcc}
\hline & \multicolumn{2}{c}{ Percentage } \\
& RSA & UK \\
& $(n=256)$ & $(n=420)$ \\
\hline Factors - Human & & \\
Colleagues' lack of statistical knowledge & 42 & 33 \\
Colleague's lack of confidence in statistical methods & 20 & 20 \\
Respondent's own lack of confidence in statistical & & \\
methods & 13 & 12 \\
Factors - Technical & & \\
Lack of appropriate data & 35 & 28 \\
Lack of consultative/technical support & 29 & 18 \\
Lack of appropriate software & 28 & 19 \\
Inadequate access to computer facilities & 9 & 9 \\
Oaher & 22 & 13 \\
No hinderances & 16 & 21 \\
Total number of mentions & 506 & \\
(excluding No hinderances) & & \\
\hline
\end{tabular}

than technical barriers. At least $16 \%$ of user respondents saw no hinderances to their further usage of statistical methods.

It is worth noting that the percentage of respondents who identify with the inhibiting factors (between $20 \%$ and $40 \%$ ) are significantly fewer than the percentage of respondents who identify with the benefits of using statistical methods (between 55\% and 70\%). A similar trend existed in the UK findings.

\section{Available support systems}

The lack of appropriate statistical software was cited as an inhibiting factor by almost $28 \%$ of respondents. Established in Table 9 is the usage level of a selection of commonly available statistical software packages.

It is clear that the majority of user respondents (91\%) rely on a spreadsheet and to a lesser extent on a database package (44\%) for their statistical analysis. Neither of these packages are custom-made statistical systems, although spreadsheets have a limited number of basic statistical functions. Statgraphics is the most frequently used generalpurpose statistical package, but only by $22 \%$ of user respondents. The low usage of established statistical software systems confirms the finding that users perceive there to be a lack of appropriate statistical software (refer Table 8).

The lack of consultative/technical support was also identified in Table 8 as a significant inhibiting factor. This study found that only $33 \%$ of user respondents have access to some form of statistical support unit within their organization. The majority of user respondents $(64 \%)$ do believe that there is a need for a statistical support unit or consultant to whom they can refer for statistical advice.

\section{Educational pointers}

The second objective of this study was to examine the offerrings of statistical topics in South African management education programmes. In this regard, Statistics courses directed at management students should endeavour to address topics considered relevant by the end-user community.
Table 9 Percentage of respondents using statistical software packages

\begin{tabular}{lc}
\hline Software packages & $\begin{array}{c}\text { Percentage } \\
(\mathrm{n}=256)\end{array}$ \\
\hline BMDP & 0 \\
SAS & 13 \\
SPSS/SCSS & 6 \\
MINITAB & 0 \\
GENSTAT & 3 \\
STATGRAPHICS & 22 \\
LOTUS 123/spreadsheet & 91 \\
DBASE III +/other database & 44 \\
Other & 15 \\
\hline
\end{tabular}

As an aid to course design, respondents were requested to indicate the appropriate location in an applied statistics course for each of 13 topics. Table 10 reflects the percentage of respondents who classified each topic as either core, an elective, or to be excluded from an applied business statistics programme.

From Table 10, it would appear that there is no single statistical technique that the clear majority of user respondents (over 90\%) wish to see excluded from a Statistical Methods course for managers.

The statistical methods which are considered fundamental by over $75 \%$ of user respondents and should be taught in a core statistical methods course are: data collection and presentation (96\%); probability analysis (83\%); regression and correlation (79\%); and forecasting methods $(76 \%)$. There is more support for confidence intervals (66\%); hypotheses testing (61\%) and sample survey design (48\%) techniques to be covered in a core course rather than as an elective.

Table 10 Statistical methods course content

\begin{tabular}{|c|c|c|c|c|}
\hline & \multicolumn{4}{|c|}{$\begin{array}{l}\text { Topic classification } \\
\qquad(n=256)\end{array}$} \\
\hline & Core & $\begin{array}{c}\text { Elec- } \\
\text {-tive } \\
(\% \text { of re }\end{array}$ & $\begin{array}{l}\text { Ex- } \\
\text { clude } \\
\text { esponde }\end{array}$ & $\begin{array}{l}\text { No } \\
\text { opinion } \\
\text { nts) }\end{array}$ \\
\hline \multicolumn{5}{|l|}{ Preferred core topics } \\
\hline Data collection and presentation & 96 & 3 & 0 & 1 \\
\hline Probability analysis & 83 & 14 & 0 & 3 \\
\hline Regression and correlation & 79 & 16 & 0 & 5 \\
\hline Forecasting models & 76 & 20 & 0 & 4 \\
\hline Confidence intervals & 66 & 22 & 2 & 10 \\
\hline Hypothesis tests & 61 & 32 & 0 & 7 \\
\hline Sample survey design & 48 & 36 & 3 & 14 \\
\hline \multicolumn{5}{|l|}{ Preferred electlve topics } \\
\hline Contingency tables & 34 & 44 & 5 & 17 \\
\hline Index numbers & 33 & 42 & 8 & 16 \\
\hline Quality control & 30 & 49 & 5 & 16 \\
\hline Non-parametric tests & 22 & 51 & 7 & 20 \\
\hline Experimental design models & 19 & 52 & 11 & 18 \\
\hline Multivariate models & 9 & 31 & 5 & 55 \\
\hline
\end{tabular}


There is clearer evidence to suggest, by examining Table 10 , that the techniques of contingency tables analysis; index numbers; quality control; non-parametric tests; experimental design models; and multivariate models should be offered as electives. There was a large non-response (55\%) to the course positioning of topics on multivariate models. This can be ascribed to the relative recent introduction of these topics into management education programmes and hence the lack of knowledge of what these topics entail by a significant proportion of user respondents.

\section{Discussion and conclusions}

In this study it was established that over $60 \%$ (63\%) of management respondents used some form of statistical analysis in their decision-making domain. A similar level of penetration (67\%) was reported in the UK study by Naudé et al. (1991). Frequent and wide-scale usage of statistical methods is limited to only three areas, namely data collection and presentation, forecasting models and regression and correlation. The remainder of statistical techniques surveyed had both low regular usage, and a small user base. The potential for future frequent usage appears limited to those statistical methods which are currently frequently used, in particular, forecasting models. Only probability analysis and quality control from amongst the list of infrequently used methods, are considered to possess greater potential for future frequent use. Further research on usage levels could correlate the strategic importance of management decisions with the prerequisite need to employ statistical methods.

It is not possible to conclude about relative changes in the usage level of statistical techniques over time due to varying sampling procedures, choice of techniques and methods of analysis employed in earlier studies cited. However, a comparison between Table 1 (Summary of previous studies: 1977-1990) and Table 5 (1992 Study) indicates consistent usage of a core of statistical techniques (descriptive statistics and display methods, regression analysis and forecasting methods). The balance of the statistical methods remain largely underutilized. Notwithstanding the significant proportion of users (60\% to $70 \%$ ) who derived benefits from the use of statistical methods, the difficulties encountered (by up to approximately $40 \%$ of users) and lack of greater benefit awareness (by between $30 \%$ and $40 \%$ of users) demand that further attention be paid to minimizing these obstacles on the one hand, and promoting the benefits on the other.

The most notable reason for this situation is still human orientated, namely a lack of knowledge and consequently confidence, by a user's colleagues with whom they need to interact in the exchange of statistical information. Technical issues also play a significant role as barriers to greater usage. The three most significant technical barriers are: the lack of appropriate data, the lack of consultative/technical support, and the perceived lack of appropriate statistical software. These issues are clearly inter-related. A consultative/technical support service could serve to familiarize users with suitable statistical software packages and advise on the design of databases to reduce the likelihood of data not being available in the format and quantity required for specific statistical analyses. Such support services would consequently promote confidence in the use and interpretation of statistical information. Thus, by addressing the lack of statistical consultative/technical support services within organizations, it may well be possible to contribute significantly to the greater utilization of statistical methods within management decision making.

These findings also have significant implications for statistics educators in the field of management education. In this study it was found that all respondents agreed that an appreciation of statistical methods in any management education programme is necessary. The question then becomes one of how to 'package the product' to promote greater utilization in practice. For managers to become users of statistical methods, the instructional modes employed must promote competency and demonstrate relevance.

According to Simms \& Sauser (1985: 51), management students, in particular MBA's, have been criticized for possessing knowledge, but failing to display competency which is the skill of applying what has been learnt. This points towards a need to re-appraise the instruction modes employed in promoting statistical expertise amongst management students. The oft quoted reason of a manager's lack of confidence in applying these techniques is clear evidence that less than appropriate learning methods have been used in the past. Greater emphasis should possibly be placed on andragogic leaming principles which encourage self-discovery. Extensive use of assignments and practical projects promote competency rather than knowledge acquistion only. While the lecture method is useful for imparting basic knowledge of statistical methods, greater emphasis should be placed on the practice of statistics during the learning process. This should promote confidence in the understanding and use of techniques as well as expose students of management to the wide spectrum of application areas and hence also demonstrate relevance.

The discipline of applied statistics must be seen in the context of decision support. In order for managers to integrate statistical thinking into the decision-making process, statistical methods and reasoning must be closely integrated with functional management disciplines. This could be done either by introducing statistics concepts within a functional discipline, or designing a Statistical Methods programme which is applications-driven instead of technique-driven. A further suggestion is the offering of specialist electives which focus on statistical methods relevant to specific functional areas. Thus, increased statistical usage may result from both a change in instruction mode and material orientation.

Curriculum design need also be examined in the light of factors identified in Table 8 as limiting greater usage of the discipline in practice. Following from the significant number of users who are restricted by the lack of appropriate data, management education programmes should include material on the organization and structuring of data capturing systems as part of a statistical methods programme. Statistical courses should include, as a core component, a section on data requirements for different statistical methods and data collection techniques to acquire the needed data. This 
practice may result in managers developing and implementing database structures within their decision domains to ensure that the required data for statistical analysis is available when required. This section should be integrated with computer-related database systems. It is also clear from the findings in Table 9 that users are unfamiliar with statistical software packages. By adopting andragogic instructional modes, familarization with available statistical software would be an integral component of such learning methods.

The discipline of statistics has much to offer management as an effective decision-support service, but there is still much that needs to be done by educators in statistics to promote greater usage of the discipline in management. This study sought to provide pointers in this review process.

\section{References}

Coccari, R.L. 1989. 'How quantitative business techniques are being used', Business Horizons, July-August, pp.70-73.

Green, T.B., Newson, W.B. \& Jones, S.R. 1977. 'A survey of the application of quantitative techniques to production/operations management in large corporations', Academic Management Journal, Vol. 20: 669-676.

Juritz, J.M., Money, A.H., Affleck-Graves, J. \& Du Toit, P.S. 1988. 'A survey of the statistical methods used in business and industry in South Africa', SAJHE, Vol. 2, No. $1: 57-64$.

Kathawala, Y. 1988. 'Applications of quantitative techniques in large and small organisations in the United States: an empirical analysis'. Journal of Opl.Res.Soc, Vol. 39, No. 11: 981-989.

Naude, P., Stray, S. \& Wegner, T. 1991. 'The penetration of quantitative methods into management decision making in the United Kingdom', OMEGA, Vol. 19, No. 5 : 447-458.

Pridmore, W.A. \& Reese, R.A. 1988. 'The institute survey 1987: a study of the characteristics of IOS membership (Part 1)', The Professional Statistician, Vol. 7, No. 5: 2-6.

Simms, R.R. \& Sauser, W.I. 1985. 'Guiding principles for establishing competency based business curriculum', Journal of Management, Vol. 4, No. 5: 51-64.

Vandell, R.F. 1970. 'Management evolution in the quantitative world', Harvard Business Review, Jan-Feb., pp.5-14.

Vatter, W.J. 1967. 'The use of operations research in American companies', Accounting Review, Vol. 42: 721-730.

Wegner.T. 1983. 'A survey of quantitative methods in South African management', S.Afr.J.Bus.Mgmt. Vol. 14, No. 3: 120-124.

Wisniewski, M., Jones, C., Halikias, J., Bourantas, D., Kristensen, K., Madsen, H. \& Ostergaard, P. 1990. 'The use of management science techniques in Europe: a preliminary report', EMSS Working Paper no. 2, November, Institut for Informationsbehandeling, ISSN 0905-1392. 